\title{
Rate and Synchrony of Seed Germination Influence Growth of Hydroponic Lettuce
}

\author{
Ahmet Korkmaz ${ }^{1}$ and Wallace G. Pill ${ }^{2}$ \\ Delaware Agricultural Experiment Station, Department of Plant and Soil \\ Sciences, University of Delaware, Newark, DE 19717-1303 \\ Bruce B. Cobb ${ }^{3}$ \\ ARC Greenhouses, Shiloh, NJ 08353 \\ Additional index words. Lactuca sativa, pregerminated seed, pelleted seed, fluid drilling, \\ slant test
}

\begin{abstract}
The effect of seed germination rate, or of seedling emergence rate, was studied in relation to subsequent plant growth of 'Cortina' lettuce (Lactuca sativa L.). Seedling growth response to selection by time of germination was assessed by imbibing seeds at 5 ${ }^{\circ} \mathrm{C}$ to increase the time range for germination. Germinated seeds were removed daily and transferred to "slants" (germination paper held at $20^{\circ}$ from vertical) at $15{ }^{\circ} \mathrm{C}$. Five days after each transfer, root and hypocotyl lengths were measured. As days required for germination increased, root lengths decreased and hypocotyl lengths increased, resulting in no change in total seedling length. The relation between rate of seedling emergence from raw or pelleted seeds of the same lot and shoot fresh weight was examined using commercially practiced hydroponic techniques. Shoot fresh weight at 10 and 21 days after planting was related inversely and linearly to the day of emergence for both seed treatments. In the same study, the coefficient of variation of shoot fresh weight was positively related to time of seedling emergence only at 10 days. Germinated seeds were selected after 1 and 2 days of imbibition; subsequent seedling emergence rate and shoot fresh weight at 25 days were recorded. First-day germinated seeds had faster and more synchronous emergence, and produced heavier and more uniform shoots. Discarding slow-to-germinate seeds should enhance seedling emergence and growth.
\end{abstract}

The increase in dry weight of lettuce is exponential for a large part of the growth cycle (Nichols, 1971). Variation in plant size increases as the crop matures, larger plants in the population continuing to secure proportionally more of the available resources up to canopy fill (Benjamin, 1990). Thus, variation in the time of germination and seedling emergence directly contribute to variation in plant maturity.

Differences in emergence rate, seedling growth, and head size were correlated with differences in lettuce seed vigor, as measured by a slant test (Smith et al., 1973b). Wurr and Fellows (1983) confirmed that variability of field-grown lettuce head weight was positively related to variability in time to seedling emergence.

\footnotetext{
Received for publication 12 Mar. 1998. Accepted for publication 9 July 1998. Published as miscellaneous paper 1623 of the Delaware Agricultural Experiment Station and Contribution 337 of the Dept. of Plant and Soil Sciences. Mention of trade names in this publication does not imply endorsement by the Delaware Agricultural Experiment Station of products named, nor criticism of similar ones not named. The cost of publishing this paper was defrayed in part by the payment of page charges. Under postal regulations, this paper therefore must be hereby marked advertisement solely to indicate this fact. ${ }^{1}$ Graduate Research Assistant. Current address: Dept. of Horticulture, Clemson Univ., Clemson, SC 29634. ${ }^{2}$ Professor; to whom reprint requests should be sent.
} ${ }^{3}$ Owner and Operator, ARC Greenhouses.
For field-grown lettuce, variation in time to seedling emergence above the soil surface can result from variations in seed vigor, planting depth, and seedbed microclimate. Both edaphic and aerial microclimates may be controlled in the greenhouse, and are therefore less variable than in the field. Consequently, the effects of seed vigor on variation in seedling emergence time and subsequent growth may be more pronounced in hydroponic lettuce production than in field production.

Lettuce development during hydroponic culture can be divided into four stages beginning at planting: stage 1 ends with full expansion of first true leaves; stages 2, 3, and 4 extend to a) appearance of leaves 4 or 5 ; b) close spacing of plants in the hydroponic troughs; and c) wide and final spacing of plants in the hydroponic troughs, respectively. One of us (B.B.C.), a commercial hydroponic lettuce grower, observed that single sowings of high-quality pelleted seeds typically can result in $18 \%$ culling of small plants at the end of stage 2 . Further culling at the end of stages 3 and 4 can be $5 \%$ and $22 \%$, respectively, primarily attributable to low-weight plants.

In hydroponic lettuce production, pelleted seeds typically are sown into phenolic foam cubes. However, germinated (pregerminated) seeds can be sown using the fluid drilling technique (Pill, 1991). In this latter method, seed selection on the basis of newly emerged radicles can be used to improve seedlot vigor, since germination rate and subsequent performance are positively correlated (Finch-Savage, 1986; Finch-Savage and McQuistan, 1988). Finch-Savage (1986) noted that in cauliflower (Brassica oleracea var. botrytis L.), leek (Allium porrum L.), and onion (Allium сера $\mathrm{L}$.), seedling length decreased and the coefficient of variation (Cv) of seedling length increased with increasing number of days of imbibition required for germination. Slowgerminating seeds produced fewer normal seedlings than fast-germinating seeds. Germination rate within a carrot (Daucus carota $\mathrm{L}$.) seedlot was related positively to vigor, percent emergence, and seedling weight and negatively related to the spread of emergence times and CV of seedling weights (Finch-Savage and McQuistan, 1988). Therefore, selecting and sowing rapidly germinating seeds from a lettuce seedlot might produce a more uniform crop of mature heads.

Our first objective was to confirm the relationship between the time required for germination and seedling growth of lettuce. Second, using commercially practiced hydroponic techniques, we sought to establish the relationship between time of seedling emergence and variation of shoot size at different stages of lettuce development. Our third objective was to determine the effect of sowing raw, pelleted, or germinated seeds on variation in lettuce shoot size.

\section{Materials and Methods}

Pelleted and raw seeds of 'Cortina' lettuce from the same seedlot were acquired from Leen de Mos (Gravenzande, The Netherlands).

Expt. 1. Germination of raw seeds at $5 \mathrm{vs.}$ $20{ }^{\circ} \mathrm{C}$. Five replications of 50 raw seeds each were placed in transparent polystyrene boxes $(12 \times 8 \times 2 \mathrm{~cm})$ on double layers of germination paper (Seed Germination Blotters No. 385; Seedburo, Chicago) that were moistened with deionized water. A preliminary experiment established that light was unnecessary for germination at $20^{\circ} \mathrm{C}$. Thus, raw seeds were subjected to continuous $20^{\circ} \mathrm{C}$ (International Seed Testing Association, 1985) or continuous $5{ }^{\circ} \mathrm{C}$ in darkness; the lower temperature was used to increase the range in germination time. Each day, germinated seeds were counted and removed. From these counts, final germination percentage (FGP) and its angular transformation (arcsine $\sqrt{\mathrm{FGP}}$ ), days to $50 \%$ FGP $\left(\mathrm{G}_{50}\right)$, and days between $10 \%$ and $90 \%$ FGP $\left(\mathrm{G}_{10-90}\right)$ were calculated.

Expt. 2. Effect of time of germination of raw seeds on subsequent seedling growth. Seedling growth (an indication of vigor) was measured using a modification of the "slant test" (Smith et al., 1973a). Raw seeds were germinated in darkness at $5{ }^{\circ} \mathrm{C}$ as described above. Seeds that germinated on successive days (first to fifth) were transferred to "slants." Germination papers were cut into $9.5 \times 14.5$ $\mathrm{cm}$ rectangles and a pencil line was drawn 1.5 $\mathrm{cm}$ from the edge across the longer dimension to provide a guide for placing the germinated seeds in a straight line. The papers were placed on $10.0 \times 15.0 \times 0.2-\mathrm{cm}$-thick plexiglass sup- 
port slants, then soaked in half-strength Hoagland solution (Hoagland and Arnon, 1950). Twenty seeds were selected from each day of germination (1-5) and spaced equally on the pencil line with the longitudinal axis of the seed along the line. The slants were placed randomly in a $36 \times 23 \times 5 \mathrm{~cm}$ plastic growth box (Stewart Plastics, Croydon, U.K.) and were held at $20^{\circ}$ from vertical by grooves cut in plexiglass support rails in the bottom of the boxes. Seeds for each day of selection were replicated four times in different growth boxes. Half-strength Hoagland solution was poured into the bottom of each of the four boxes (replications); tightly fitting transparent dome lids maintained $\approx 100 \%$ relative humidity $(\mathrm{RH})$. The slants were maintained at $15{ }^{\circ} \mathrm{C}$ under fluorescent lamps [photosynthetic photon flux $\left.(P P F)=210 \mu \mathrm{mol} \cdot \mathrm{m}^{-2} \cdot \mathrm{s}^{-1}\right]$ in a growth chamber (Conviron E15, Winnipeg, Canada).

Five days after each transfer to the slants, hypocotyl and root lengths of each seedling were measured using a vernier caliper. From these data, total seedling lengths (hypocotyl plus root lengths), and CV of root, hypocotyl, and seedling lengths were calculated. All data from this randomized complete-block study were subjected to analysis of variance (ANOVA)

Expt. 3. Effects of time to seedling emergence of raw seeds on stage 1 and 2 shoot fresh weights. This study was designed to establish the relationship between time of seedling emergence and shoot fresh weight (SFW) at 10 and $21 \mathrm{~d}$ after planting (DAP), the end of stages 1 and 2, respectively. Each treatment combination of this 2 (pelleted vs. raw seed) $\times 2$ (stage 1 vs. 2) factorial treatment design occupied a phenolic foam tray (338 cubes of $22 \times 22 \times$ $37 \mathrm{~mm}$ depth; Smithers Oasis, Kent, Ohio) with four replications (trays). A single seed was placed in the 7.5-mm-diameter $\times 10$ - $\mathrm{mm}$ deep depression in each cube and covered with fine exfoliated vermiculite (grade 5; W.R. Grace, Cambridge, Mass.). The 16 trays were arranged in a randomized complete block under a greenhouse mist system providing water for $10 \mathrm{~s}$ every 6 min during daylight hours. The experiment was conducted under natural photoperiods (April) at $21{ }^{\circ} \mathrm{C}$ day/13 ${ }^{\circ} \mathrm{C}$ night.

Time for seedling emergence (hypocotyl arch visible) in each cube was monitored twice daily. At the end of stage 1, shoots from each cube were cut at the vermiculite surface and SFW was determined. Day of seedling emergence, SFW, and CV of SFW (CVSFW) for each day of seedling emergence were subjected to ANOVA.

The remaining trays were removed from the mist system and maintained under the same light and temperature regime, but were provided with hydroponic solution through subsurface irrigation, as described by Korkmaz et al. (1998). The solution, maintained at $1-\mathrm{cm}$ depth in a frame lined with white polyethylene, was replaced on alternate days. At the end of stage 2, shoots were harvested and SFW and CVSFW analyzed as described for stage 1 .

Expt. 4. Effect of initial shoot length on stage 3 and 4 shoot fresh weights. Six phenolic foam trays were sown with raw and pelleted seeds, and maintained as described for Expt. 3 . At 21 DAP, all cubes were separated, and seedling shoot lengths from raw and pelleted seed were estimated by measuring the distance from the top of the cube to the extended tip of the longest leaf. Three shoot length classes were established $($ short $=<4.0 \mathrm{~cm} ;$ medium $=$ 4.5 to $5.5 \mathrm{~cm}$; and long $=>6.0 \mathrm{~cm}$ ).

These grouped seedlings were transported to a commercial hydroponic lettuce operation (ARC Greenhouses, Shiloh, N.J.) and grown to the end of stages 3 and 4 (45 and 66 DAP, respectively). The 2 (raw vs. pelleted seeds) $\times$ 3 (short-, medium-, and long-stage 2 shoots) factorial treatment design with four replications was arranged as a split block, with each treatment within a replication consisting of two adjacent hydroponic troughs $(6.5 \mathrm{~cm}$ wide $\times 3.2 \mathrm{~cm}$ tall $\times 300 \mathrm{~cm}$ long; Rehau Co., Montreal).

Seedlings were placed at $7.5 \times 7.5 \mathrm{~cm}$ by placing the foam cubes in adjacent $3.0 \times 3.0$ $\mathrm{cm}$ openings in the lid over each trough and by pushing adjacent troughs together. Plants were provided a continuously circulated film of nutrient solution formulated as described above. They were grown at $18^{\circ}$ day $/ 9^{\circ} \mathrm{C}$ night under natural light supplemented by HPS lamps with a flux density of $0.7 \mathrm{~W} \cdot \mathrm{m}^{-2}$ from 0700 to 1900 HR. At the end of stage 3 (15 May), shoots of alternate plants in each trough (except those from plants at the trough ends) were cut at the cube surface, and SFW was recorded within a few minutes of harvest. The between-trough spacing was now doubled and the plants were grown at $15 \times 15 \mathrm{~cm}$ for an additional 3 weeks. At the end of stage 4 (5 June), SFW of all stage 4 plants, except for plants at the ends of troughs, was determined. The SFW and CVSFW of stage 3 and 4 plants were subjected to ANOVA.

Expt. 5. Effects of seed preparation on seedling emergence and growth. Raw, pelleted, or selected pregerminated seeds were compared in this experiment. Raw seeds were germinated in darkness on water-saturated germination paper at $10{ }^{\circ} \mathrm{C}$. Seeds that had germinated by $24 \mathrm{~h}$ after sowing were removed from the germination tray, leaving seeds that would be selected for germination on the following day (day- 2 seeds). To provide day-1 seeds, more seeds were sown in another tray $24 \mathrm{~h}$ after sowing the day- 2 germinated seeds. Two $d$ after sowing the day- 2 germinated seeds, germinated seeds with radicles $<2$ $\mathrm{mm}$ long from both trays were collected using forceps, and stored in a humid container for 1 $\mathrm{h}$ or less, then planted.

Raw and pelleted seeds, and day- 1 and day-2 germinated seeds, were planted into 10 $\times 10$-cube foam trays within a few hours of each other, and the seeds covered with fine (grade 5) vermiculite. The trays, arranged as a randomized complete block with four replications, were placed under intermittent mist. The study was conducted under natural light (June to early July) in a greenhouse set at $21^{\circ} \mathrm{C}$ day/ $13{ }^{\circ} \mathrm{C}$ night. Time of seedling emergence (hypocotyl arch visible) was monitored twice daily. From emergence counts, final emergence percentage (FEP) and its angular transformation (arcsine $\sqrt{F E P}$ ), days to $50 \%$ FEP $\left(\mathrm{E}_{50}\right)$, and days between $10 \%$ and $90 \%$ FEP $\left(\mathrm{E}_{10-90}\right)$ were calculated.

One week after sowing seeds, all foam trays were removed from under the mist system and subirrigated with hydroponic solution. At the end of Stage 2, SFW was determined. Emergence variables SFW and CVSFW were subjected to ANOVA.

\section{Results and Discussion}

Expt. 1. Germination of raw seeds at $5 \mathrm{vs}$. $20{ }^{\circ} \mathrm{C}$. While raw seeds had 100 FGP at both 5 and $20^{\circ} \mathrm{C}$, germination at $5{ }^{\circ} \mathrm{C}$ significantly increased both $\mathrm{G}_{50}$ (from 0.5 to $6.4 \mathrm{~d}$ ) and $\mathrm{G}_{10-90}$ (from 0.8 to $1.9 \mathrm{~d}$; data not shown). Percentage germination on successive days was 75.2 and 24.4 at $20^{\circ} \mathrm{C}$, and $0.2,0.6,1.2$, $2.1,22.6,55.3$, and 17.6 at $5^{\circ} \mathrm{C}$.

Expt. 2. Effect of time of germination of raw seeds on subsequent seedling growth. The 5 -d slant test revealed that seedling root length decreased as time to germination increased (Fig. 1). Smith et al. (1973a) reported that root length at $25^{\circ} \mathrm{C}$ in the dark, $3 \mathrm{~d}$ after transfer of seeds to slants, correlated well with emergence rate, seedling growth, and head size of field-grown lettuce. They also established that lettuce seedling vigor varied positively with seed weight. Since our seedlot had been graded

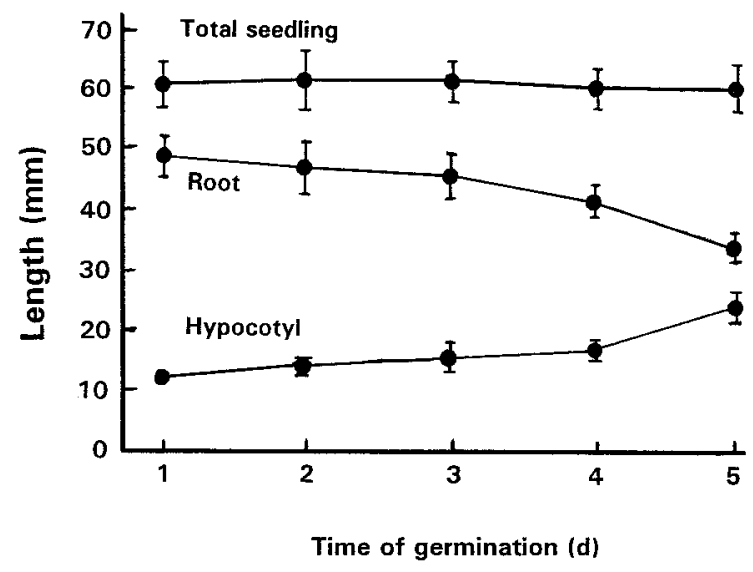

Fig. 1. Effect of time of seed germination on length of root, hypocotyl, and seedling (root + hypocotyl) lengths of 'Cortina' lettuce after $5 \mathrm{~d}$ of growth. Vertical bars represent standard deviations. 
for size uniformity by the supplier, differences in seedling vigor could not have been related to seed size.

As root length decreased, hypocotyl length increased, indicating that time to germination altered the root: shoot growth ratio. However, total seedling length was unaffected by time of seed selection. The increase in hypocotyl length at the expense of root length may reduce the ability of seedlings to become anchored in the seedbed and extract water and nutrients.

Time of germination had no effect on $\mathrm{CV}$ of hypocotyl, root, or seedling lengths (5-d mean values of $14.0 \%, 16.8 \%$, and $11.0 \%$, respectively; data not shown). Thus, length, but not uniformity, of root growth was reduced as time to germination increased. In contrast, Finch-Savage (1986) reported that seedling length decreased and CV of seedling length increased with time required for germination of cauliflower, leek, and onion seeds. Gray and Steckel (1983), likewise reported that variability in root length of carrot seedlings from the slant test provided a good estimate of variability in seedling size.

Expt. 3. Effects of time to seedling emergence of raw seeds on stage 1 and 2 shoot fresh weights. At the end of stage 1, SFW of seedlings from raw seeds was generally greater than that of those from pelleted seeds (Fig. 2). The seed coating may have delayed germination (Valdes and Bradford, 1987) and thus reduced seedling SFW. Raw and pelleted seeds produced similar CVSFW at 10 DAP when seedlings emerged at $<6$ DAP, but raw seeds exhibited less variability in SFW than did pelleted seeds when seedlings emerged at $>6$ DAP. By the end of stage 2, SFW and CVSFW were unaffected by pelleting (Fig. 3).

For both raw and pelleted seeds, SFW at the end of stage 1 (Fig. 2) and 2 (Fig. 3), was inversely and linearly related to day of seedling emergence. These results are in general agreement with those of Smith et al. (1973b), who found that seedlings from low-vigor lettuce seeds emerged later and produced smaller seedlings.

The CVSFW at the end of stage 1 (Fig. 2) increased as day of seedling emergence increased (from $\approx 25 \%$ at day 4 to $\approx 35 \%$ to $45 \%$ at day 8), but was not affected at 21 DAP (mean $=20 \% \mathrm{cv}$; Fig. 3 ). Therefore, seedlings that emerged late had lower SFW than did those that emerged early (at the end of stages 1 and 2). The decrease in CVSFW from the end of stage 1 to the end of stage 2 was more pronounced in the former.

Expt. 4. Effects of initial shoot length on stage 3 and 4 shoot fresh weights. Pelleting had no effect on SFW and CVSFW at the ends of stages 3 and 4 . Therefore, we show the average responses of pelleted and raw seeds at the end of stages 3 and 4 (Figs. 4 and 5, respectively) as a function of shoot length at the end of stage 2. The SFW increased and the CVSFW decreased at the ends of stages 3 and 4 , as initial seedling length increased. Since a) SFW at the end of stage 2 was inversely related to day of seedling emergence (Fig. 2), and b) SFW at the end of stages 3 (Fig. 4) and 4 (Fig. 5) was directly proportional to seedling size at

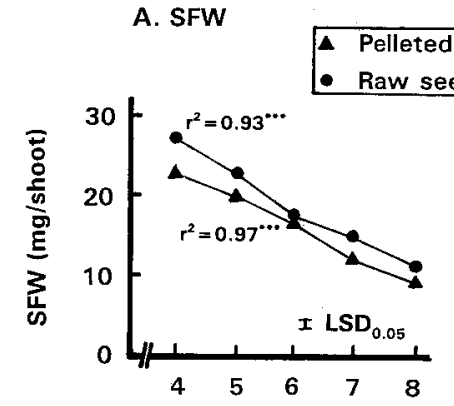

B. CV

Time of seedling emergence (d)

Fig. 2. Effect of time of seedling emergence from raw and pelleted 'Cortina' lettuce seeds on (A) shoot fresh weights (SFW), and (B) their coefficients of variation (CV) at the end of stage 1 (10 d after planting).

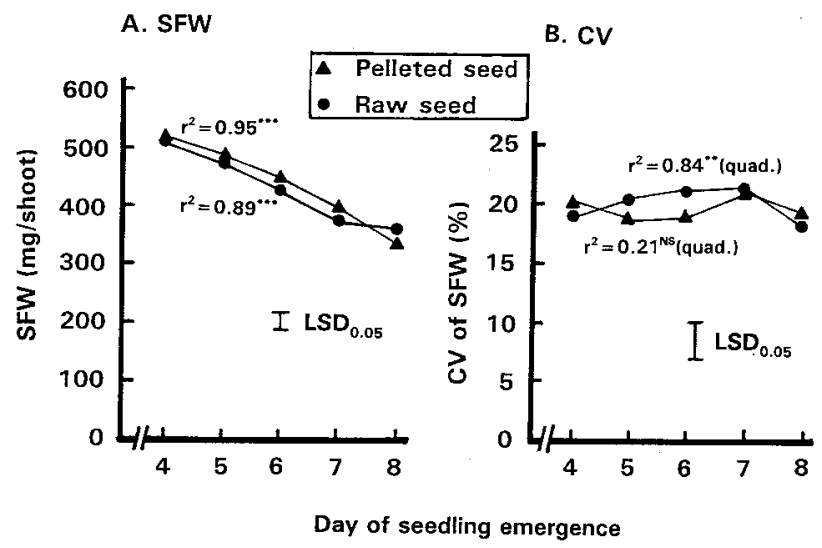

Fig. 3. Effect of time of seedling emergence from raw and pelleted 'Cortina' lettuce seeds on (A) shoot fresh weights (SFW), and (B) their coefficients of variation (Cv) at the end of stage 2 ( $21 \mathrm{~d}$ after planting).

A. SFW

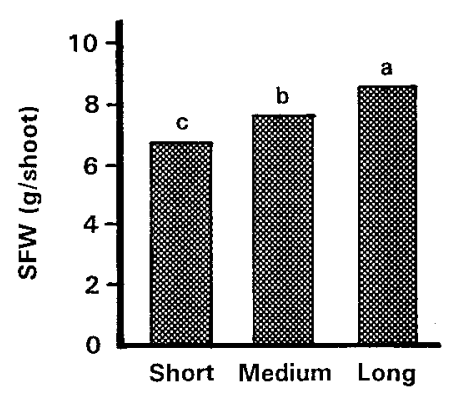

B. CV

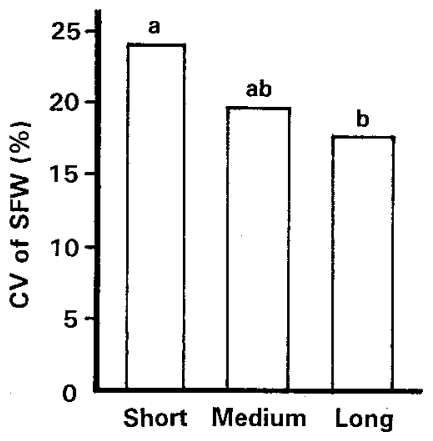

Seedling shoot length at the end of stage 2

Fig. 4. Effect of shoot length of 'Cortina' lettuce at the end of stage 2 on (A) shoot fresh weights (SFW), and (B) their coefficients of variation (Cv) at the end of stage 3 (42 d after planting). Shoot length was measured from the top of the phenolic foam cube to the tip of the fully extended longest leaf: short $=\langle 4.0$ $\mathrm{cm}$; medium $=4.5$ to $5.5 \mathrm{~cm}$; and long $=>6.0 \mathrm{~cm}$. Mean separation by LSD $(P \leq 0.05)$.

the end of stage 2, early-emerging seedlings probably would have been larger at final harvest, as shown by Smith et al. (1973b). In our study, however, we did not determine the relationship between time of seedling emergence and SFW at final harvest. Lettuce follows a logistic growth curve, with individual plants completing their growth at about the same maximum weight (Currah, 1978). Consequently, initial differences in seedling size will be maintained during exponential growth. These differences will lessen as the crop ap- proaches maturity or as final harvest is delayed. By grouping seedlings into arbitrary shoot length classes at the end of stage 2, we may have accentuated the inverse relationship between SFW and CVSFW observed at the end of stage 1 (Fig. 2). Selecting for larger seedlings at the end of stage 2 , before placement of the phenolic cubes in the hydroponic troughs, would have resulted in larger and more uniform heads.

Expt. 5. Effects of seed preparation on seedling emergence and growth. Day-1 ger- 
minated seeds emerged more rapidly $\left(\mathrm{E}_{50}=1.9\right.$ d) and synchronously $\left(E_{10-90}=1.0 \mathrm{~d}\right)$ than did all other seeds (Table 1). Day-2 germinated seeds had lower FEP, greater $\mathrm{E}_{50}$, and greater $\mathrm{E}_{10-90}$ than did day-1 germinated seeds. Although raw and pelleted seeds had FEP values similar to those of day-1 germinated seeds (92), their $\mathrm{E}_{50}$ values were not significantly different from, and their $\mathrm{E}_{10-90}$ values were significantly lower than, those of day-2 germinated seeds.

Asynchrony of seedling emergence $\left(\mathrm{E}_{10-90}\right)$ and CVSFW at 25 DAP were positively related in all seed treatments (Table 1). Day-2 germinated seeds had the highest, and day-1 germinated seeds had the lowest, $\mathrm{E}_{10-90}$ and CVSFW values. Quickly germinating seeds of cauliflower, leek, and onion (Finch-Savage, 1986), and carrot (Finch-Savage and McQuistan, 1988) produced markedly shorter seedlings with larger seedling length CVs relative to slowly germinating seeds. The $\mathrm{E}_{10-90}$ and CVSFW of pelleted and raw seeds were intermediate between those of day-1 and day2 germinated seeds. Pelleted seeds (the seed treatment of typical commercial practice) had higher $\mathrm{E}_{50}, \mathrm{E}_{10-90}$, and CVSFW, and lower SFW than did day-1 germinated seeds.

Germinated seeds can be delivered to the seedbed in water or gel carrier, a planting technique termed fluid drilling (Pill, 1991, 1995). Gray (1976, 1978) noted that fluid drilling of germinated lettuce seeds resulted in increased synchrony of seedling emergence in the field and increased uniformity of crop maturity in comparison with conventional drysowing of untreated seeds. We know of no reports of fluid drilling of germinated seeds for hydroponic lettuce production. Germinated seeds can be separated from nongerminated seeds by a flotation technique based on seed density differences (Taylor and Kenny, 1985). Seed treatments that increase the proportion of germinated seeds at the time of fluid drilling (Pill and Finch-Savage, 1988) should be avoided, since they synchronize the germination of seeds of varying vigor. A commercial planter has been developed for fluiddrilling singulated, germinated seeds into multicell trays (Fluid Drilling Ltd., Stratford, U.K.).

Our data show seedlings from early germinating seeds had longer roots after $5 \mathrm{~d}$ from germination than did later germinating seeds. Root length would appear to be an appropriate estimate of seed vigor, since root length decreased and hypocotyl length increased with increasing days to germination, seedling length remaining constant. Using commercially practiced hydroponic techniques, we observed that the first seedlings to emerge from the phenolic foam cubes produced the heaviest seedling shoots. Selection for large seedlings before placement of the phenolic foam cubes in the hydroponic troughs (at the end of stage 2) resulted in larger and more uniform heads at final harvest. Day-1 germinated seeds emerged more rapidly and uniformly, and produced heavier and more uniform seedling shoots at the end of stage 2 than did day- 2 germinated, raw, or pelleted seeds. Therefore, fluid-drill-
A. SFW

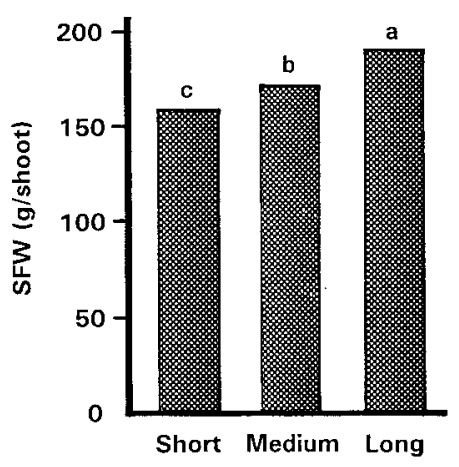

B. CV

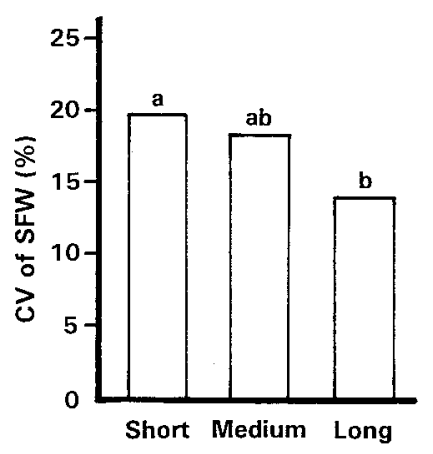

Seedling shoot length at the end of stage 2

Fig. 5. Effect of shoot length of 'Cortina' lettuce at the end of stage 2 on (A) shoot fresh weights (SFW), and (B) their coefficients of variation (CV) at the end of stage 4 (63 d after planting). Shoot length was measured from the top of the phenolic foam cube to the tip of the fully extended longest leaf: short $=<4.0$ $\mathrm{cm}$; medium $=4.5$ to $5.5 \mathrm{~cm}$; and long $=>6.0 \mathrm{~cm}$. Mean separation by $\operatorname{LSD}(P \leq 0.05)$.

Table 1. Final emergence percentage (FEP) and its angular transformation, days to $50 \%$ of FEP ( $\left.\mathrm{E}_{50}\right)$, days between $10 \%$ and $90 \%$ of FEP $\left(\mathrm{E}_{10-90}\right)$, shoot fresh weight (SFW), and coefficient of variation of SFW (CVSFW) at the end of stage 2 in response to sowing germinated (day-1 or day-2), raw, or pelleted 'Cortina' lettuce seeds.

\begin{tabular}{|c|c|c|c|c|c|c|}
\hline \multirow{2}{*}{$\begin{array}{l}\text { Seed } \\
\text { treatment }\end{array}$} & \multicolumn{2}{|c|}{ FEP } & \multirow{2}{*}{$\begin{array}{r}E_{50} \\
\text { (d) }\end{array}$} & \multirow{2}{*}{$\begin{array}{c}\mathrm{E}_{10-90} \\
\text { (d) }\end{array}$} & \multirow{2}{*}{$\begin{array}{c}\text { SFW } \\
(\mathrm{mg} / \mathrm{shoot})\end{array}$} & \multirow{2}{*}{$\begin{array}{c}\text { CVSFW } \\
(\%)\end{array}$} \\
\hline & $\%$ & [deg.] & & & & \\
\hline Germinated-day 1 & 92 & [74] & 1.9 & 1.0 & 2112 & 23.4 \\
\hline Germinated-day 2 & 65 & [54] & 4.1 & 5.1 & 1908 & 49.3 \\
\hline Raw & 91 & [73] & 3.8 & 3.5 & 1694 & 37.2 \\
\hline Pelleted & 92 & [74] & 4.8 & 2.9 & 1586 & 32.8 \\
\hline $\mathrm{LSD}_{0.05}$ & & [5] & 0.9 & 1.3 & 347 & 9.2 \\
\hline Significance & & {$[* * *]$} & $* * *$ & $* * *$ & $*$ & $* * *$ \\
\hline
\end{tabular}

Nonsignificant or significant at $P<0.05$ or 0.001 , respectively.

ing of rapidly germinating seeds from a seedlot should reduce both crop production time and the need for plant culling.

\section{Literature Cited}

Benjamin, L.R. 1990. Variation in time of seedling emergence within populations: A feature that determines individual growth and development. Adv. Agron. 44:1-25.

Currah, I.E. 1978. Plant uniformity at harvest is related to variation between emerging seedlings. Acta Hort. 72:57-68.

Finch-Savage, W.E. 1986. A study of the relationship between seedling characters and rate of germination within a seedlot. Ann. Appl. Biol. 108:441-444.

Finch-Savage, W.E. and C.I. McQuistan. 1988. Performance of carrot seeds possessing different germination rates within a seed lot. J. Agr. Sci. 110:93-99.

Gray, D. 1976. The effect of time to emergence on head weight and variation in head weight at maturity in lettuce (Lactuca sativa). Ann. Appl. Biol. 82:569-575.

Gray, D. 1978. The effect of sowing pre-germinated seeds of lettuce (Lactuca sativa) on seedling emergence. Ann. Appl. Biol. 88:185-192.

Gray, D. and J.R.A. Steckel. 1983. A comparison of methods of evaluating seed quality in carrots (Daucus carota). Ann. Appl. Biol. 103:327-334.

Hoagland, D.R. and D.I. Arnon. 1950. The waterculture method for growing plants without soil. California Agr. Expt. Sta. Circ. 47.

International Seed Testing Association. 1985. International rules for seed testing. Seed Sci. Technol. 13:443.
Korkmaz, A., W.G. Pill, and B.B. Cobb. 1998. Seed treatment and cultural practices influence seedling growth of hydroponic lettuce. HortTechnology 8:560-564.

Nichols, M.A. 1971. The effect of spacing and fertilisers on the growth of lettuce. PhD Diss., Massey Univ., New Zealand.

Pill, W.G. 1991. Advances in fluid drilling. HortTechnology 1:59-65.

Pill, W.G. 1995. Low water potential and presowing germination treatments to improve seed quality, p. 319-359. In: A.S. Basra (ed.). Seed quality: Basic mechanisms and agricultural implications. Food Prod. Press, New York.

Pill, W.G. and W.E. Finch-Savage. 1988. Effects of combining priming and plant growth regulator treatments on the synchronization of carrot seed germination. Ann. Appl. Biol. 114:383-389.

Smith, O.E., N.C. Welch, and T.M. Little. 1973a. Studies on lettuce seed quality: I. Effect of seed size and weight on vigor. J. Amer. Soc. Hort. Sci. 98:529-533.

Smith, O.E., N.C. Welch, and O.D. McCoy. 1973b. Studies on lettuce seed quality: II. Relationship of seed vigor to emergence, seedling weight, and yield. J. Amer. Soc. Hort. Sci. 98:552-556.

Taylor, A.G. and T.J. Kenny. 1985. Improvement of germinated seed quality by density separation. J. Amer. Soc. Hort. Sci. 110:347-349.

Valdes, V.M. and K.J. Bradford. 1987. Effect of seed coating and osmotic priming on the germination of lettuce seeds. J. Amer. Soc. Hort. Sci. 112:153-156.

Wurr, D.C.E. and J.R. Fellows. 1983. The effect of the time of seedling emergence of crisp lettuce on the time of maturity and head weight at maturity. J. Hort. Sci. 58:561-566. 